\title{
TWO STATEMENTS CONCERNING THE ARTICLE ON G. H. HARDY ${ }^{1}$
}

The undersigned consider that some points in the lively and interesting article of Professor Norbert Wiener on G. H. Hardy need correction. They offer no comment on what is matter of opinion, but wish to mention the following facts.

(1) Hardy was not a conscientious objector. In the First World War, he volunteered for military service under the Derby scheme.

(2) Bohr and Landau cannot correctly be described as students of Hardy. The work of all three overlapped.

(3) To say that "Hardy chose as his field the analytic theory of numbers" is to leave out of account his important work on Tauberian Theorems, on Diophantine approximation, and on Fourier series.

\section{J. E. Littlewood, G. Pólya, L. J. Mordell,}

E. C. Titchmarsh, H. Davenport

The first thing I ought to say is that I had been definitely misinformed concerning Hardy's attitude in the first World War. I regret this as well as any harm that may have been done.

While Bohr and Landau cannot be described as students of Hardy, they are certainly mathematicians who have received a maximum influence from his work so that I consider that my statement although false in detail is correct in implications.

Finally, I may be quite wrong, but I feel that Hardy's very great work on Tauberian theorems, Diophantine approximation, and Fourier series is very largely an outgrowth of his interest in analytical number theory and even tools for its development. This is in no way to minimize the importance of these pieces of work for themselves, but it is to give them the orientation which I think proper in describing Hardy's career.

NORBERT WIENER

${ }^{1}$ Norbert Wiener, Godfrey Harold Hardy, 1877-1947, Bull. Amer. Math. Soc. vol. 55 (1949) pp. 72-77. 